\title{
Unusual genome complexity in Lactobacillus salivarius JCM1046
}

Emma J Raftis ${ }^{1,2}$, Brian M Forde ${ }^{1,2}$, Marcus J Claesson ${ }^{1,2}$ and Paul W O'Toole ${ }^{1,2^{*}}$

\begin{abstract}
Background: Lactobacillus salivarius strains are increasingly being exploited for their probiotic properties in humans and animals. Dissemination of antibiotic resistance genes among species with food or probiotic-association is undesirable and is often mediated by plasmids or integrative and conjugative elements. L. salivarius strains typically have multireplicon genomes including circular megaplasmids that encode strain-specific traits for intestinal survival and probiotic activity. Linear plasmids are less common in lactobacilli and show a very limited distribution in L. salivarius. Here we present experimental evidence that supports an unusually complex multireplicon genome structure in the porcine isolate L. salivarius JCM1046.

Results: JCM1046 harbours a $1.83 \mathrm{Mb}$ chromosome, and four plasmids which constitute $20 \%$ of the genome. In addition to the known $219 \mathrm{~kb}$ repA-type megaplasmid pMP1046A, we identified and experimentally validated the topology of three additional replicons, the circular pMP1046B (129 kb), a linear plasmid pLMP1046 (101 kb) and pCTN1046 (33 kb) harbouring a conjugative transposon. pMP1046B harbours both plasmid-associated replication genes and paralogues of chromosomally encoded housekeeping and information-processing related genes, thus qualifying it as a putative chromid. pLMP1046 shares limited sequence homology or gene synteny with other L. salivarius plasmids, and its putative replication-associated protein is homologous to the RepA/E proteins found in the large circular megaplasmids of L. salivarius. Plasmid pCTN1046 harbours a single copy of an integrated conjugative transposon (Tn6224) which appears to be functionally intact and includes the tetracycline resistance gene tetM.

Conclusion: Experimental validation of sequence assemblies and plasmid topology resolved the complex genome architecture of $L$. salivarius JCM1046. A high-coverage draft genome sequence would not have elucidated the genome complexity in this strain. Given the expanding use of L. salivarius as a probiotic, it is important to determine the genotypic and phenotypic organization of $L$. salivarius strains. The identification of Tn6224-like elements in this species has implications for strain selection for probiotic applications.
\end{abstract}

Keywords: Lactobacillus salivarius, Megaplasmid, Multireplicon, Linear plasmid, Tn6224, Conjugative transposon

\section{Background}

Lactobacillus salivarius [1] is a member of the indigenous microbiota of the oral cavity and the gastrointestinal tract (GIT) of both humans and animals [2,3], and has also been isolated from human breast milk [4]. The probiotic and immunomodulatory activity of L. salivarius strains has been recently reviewed [5] and are considered to be strain-specific traits [6]. Strains of L. salivarius are genetically diverse [7] and harbour distinctive multireplicon genomes. The first genome of this species to be published $[8,9]$ was that of the well-characterised

\footnotetext{
* Correspondence: pwotoole@ucc.ie

${ }^{1}$ School of Microbiology University College Cork, Cork, Ireland

${ }^{2}$ Alimentary Pharmabiotic Centre, University College Cork, Cork, Ireland
}

strain L. salivarius UCC118 [1,10-13] whose megaplasmid pMP118 $(242 \mathrm{~kb})$ encodes genes involved in GI tract survival, fitness and probiotic activity [9-11]. L. salivarius strains from a range of environmental sources harbour diverse circular megaplasmids [7,12]. At least 10 additional $L$. salivarius genomes have been sequenced since that of strain UCC118; three of these have been completed (strains CECT 5713 [14] NIAS840 [15] and SMXD51 [16]) with two being finished to a draft quality status $[17,18]$.

Unlike circular plasmids, linear plasmids are rarely observed in lactobacilli [12] but often confer advantageous phenotypes to their hosts $[19,20]$ and have been extensively studied in Streptomyces [21,22], Borrelia [23] and 
Bacillus [24]. Linear phage genomes are also harboured by strains of Escherichia coli [25], Yersinia enterocolitica [26], Klebsiella oxytoca [27] as well as the probiotic cheese strain Lactobacillus paracasei NFBC 338 [28]. Prior to the discovery of linear megaplasmids in L. salivarius [12], a $150 \mathrm{~kb}$ linear plasmid was identified in Lactobacillus gasseri CNRZ222 [29]; but no characterization of the plasmid was performed. We previously identified linear megaplasmids in two porcine L. salivarius isolates, JCM1046 and JCM1047, and one human intestinal isolate AH43348 [12].

The conjugative transposon (CTs) Tn916 (18.5 kb) [30] and other Tn916-like elements are highly promiscuous [31], both in the lab and in natural environments [32]. They have demonstrated intra- and interspecies transfer from Lactococcus lactis [33] and Lactobacillus paracasei [34] food strains; and between streptococcal species in dental biofilms [35]. There is a growing concern that commensal bacteria may act as natural reservoirs for antibiotic resistance determinants [36] and may be responsible for transfer of antibiotic resistance to pathogens and opportunistic pathogens [37]. In addition to the introduction of additional functional modules to the host cell, CTs have further potential to influence natural selection within a bacterial population [38]. There is therefore a growing need to characterize these mobile elements, particularly in species used in food or as probiotics.

Here we present experimental evidence for a highly unusual genome architecture in L. salivarius JCM1046, a strain that harbours multiple extrachromosomal replicons of varying sizes and topologies and which has an enhanced ability to withstand the stresses associated with GIT survival [11]. The present study describes an unprecedented level of genome complexity in $L$. salivarius.

\section{Results and discussion}

Discovery of circular and linear extrachromosomal elements in L. salivarius JCM1046

Sequencing revealed that $L$. salivarius JCM1046 contains five replicons (Table 1): a $1.836 \mathrm{Mb}$ chromosome, two circular megaplasmids of 219 and $129 \mathrm{~kb}$, a linear megaplasmid of $101 \mathrm{~kb}$, and a $33 \mathrm{~kb}$ plasmid harbouring an integrated conjugative transposon (Figure 1). The complexity of this genome configuration presented extraordinary challenges for genome assembly, described below. Experimental validation of the genome structure is presented in Figure 2. L. salivarius strains JCM1047 and AH43348 were known to harbour linear megaplasmids that were presumed to be related to pLMP1046 [12] and were therefore included in these experiments.

Our original study that identified pMP1046A (then designated pMP1046 [12]) in strain JCM1046 estimated its size as $230 \mathrm{~kb}$, based on Pulsed Field Gel Electrophoresis (PFGE) [12]. However, the assembled sequence data revealed pMP1046A as closer to $220 \mathrm{~kb}$ in size. A combination of restriction digestion, PFGE and Southern hybridisation was used to validate the size of pMP1046A. ApaI was used to linearise the replicon prior to PFGE and Southern Blot analysis. Probes associated with the replication origin of pMP1046A hybridised to a band that migrated to a constant position between the $194 \mathrm{~kb}$ and $242.5 \mathrm{~kb}$ linear $\lambda$ DNA markers, which was in keeping with the expected 219,748 bp size indicated by DNA sequencing.

We identified two novel plasmids pMP1046B and pCTN1046 from the genome sequence. A large contig ( $\sim 130 \mathrm{~kb})$ was assembled that could not be experimentally determined to form part of either the chromosome or previously described plasmid content of strain JCM1046 [12]. This contig harboured plasmid-associated replication and maintenance proteins. A PCR product off the ends of this contig was generated and subsequently sequenced (data not shown) which proved that the assembled contig was circular in the cell, and it was designated pMP1046B. Under the PFGE conditions that are routinely used to visualise the plasmid content of L. salivarius strains, pM1046B had previously gone undetected $[9,40]$ possibly because it was masked by the linear replicon pLMP1046 [12].

We employed restriction digestion and S1 nuclease treatment in conjunction with PFGE and Southern Blot

Table 1 General genome features of $L$. salivarius JCM1046

\begin{tabular}{lccccc}
\hline Feature & Chromosome & pMP1046A & pMP1046B & pLMP1046 & pCTN1046 \\
\hline Replicon size (bp) & $1,836,297$ & 219,748 & 129,218 & 101,883 & 33,315 \\
GC Content (\%) & 33.1 & 32.04 & 33.87 & 30.91 & Linear \\
Topology & Circular & Circular & Circular & 5.89 & 1.3 \\
\% of genome size & 79.1 & 9.4 & 159 & 112 & 40 \\
Coding genes & 1705 & 214 & $83.6 \%$ & $82.6 \%$ & 0 \\
Coding density (\%) & $83.3 \%$ & $80.7 \%$ & 0 & 0 & 0 \\
rRNA operons & 7 & 0 & 2 & 0 & 0 \\
tRNAs & 75 & 0 & 2 & & 0 \\
Pseudogenes & 60 & 15 & & & 1 \\
\hline
\end{tabular}




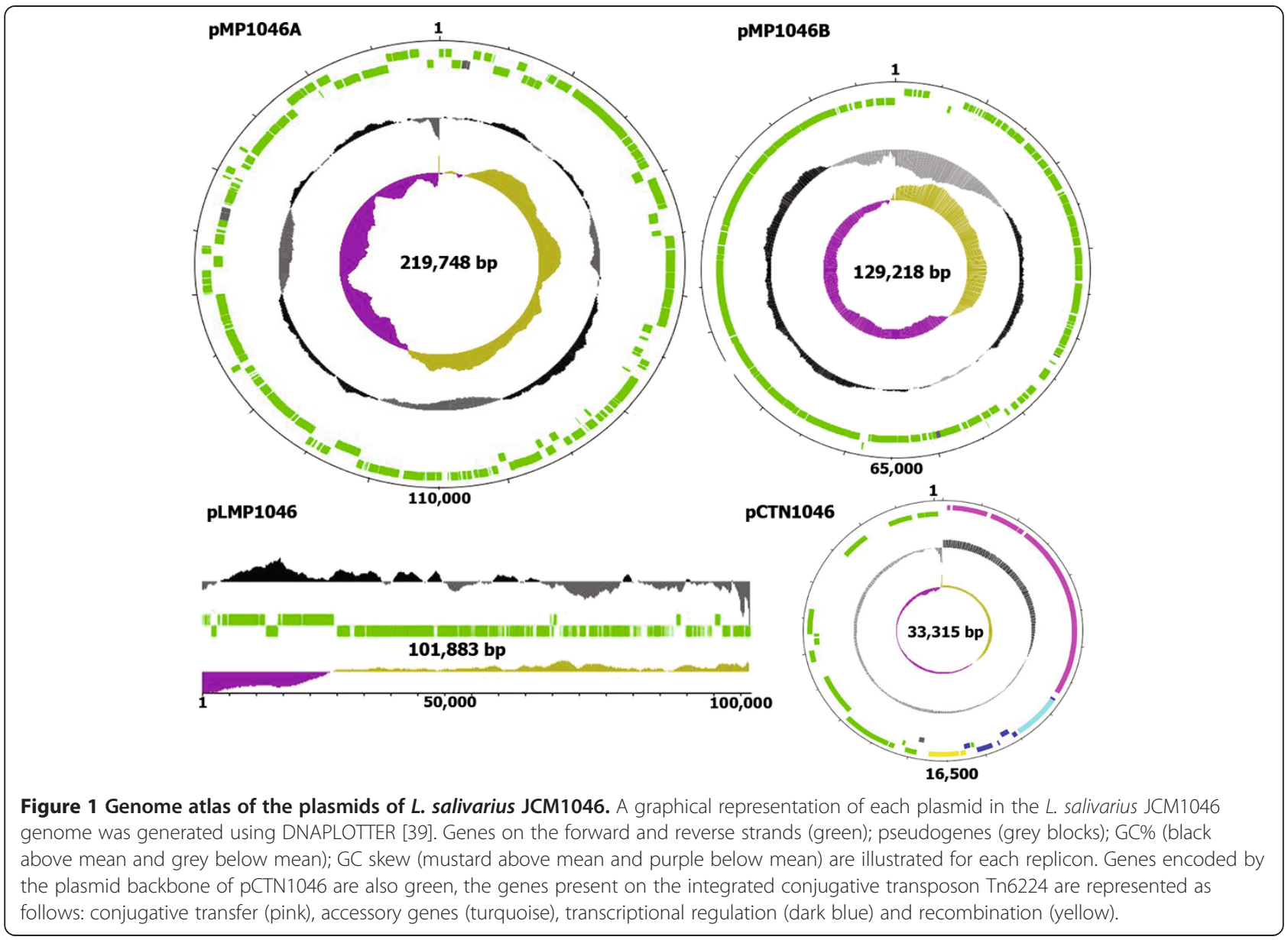

analysis to confirm the sizes and topologies of the plasmids present in JCM1046. Figure 2 panels A and B illustrate the identification of a repB-type megaplasmid in JCM1046, panels $C$ and D display the linear plasmids of JCM1046, JCM1047 and AH43348, and panels E and F illustrate the size and topolgy of pCTN1046. Chromosomal DNA bands of strains JCM1046, JCM1047 and AH43328 migrate to the equivalent of the $1 \mathrm{Mb}$ marker (Figure 2 panels A, C and E). S1 Nuclease preferentially nicks and linearises megaplasmids due to inherent torsional stresses [41]. The linearised form of the repA-type circular megaplasmids of the L. salivarius strains are indicated by the open black arrows in Figure 2 panels A, C and $\mathrm{E}$.

When an increased band intensity or band width is observed in a PFGE gel, it is often indicative of the presence of linear DNA, high copy number extrachromosomal elements or co-migrating bands of similarly sized DNA fragments [42]. Strain JCM1046 gDNA revealed high-intensity bands in the S1-treated sample at a position just below the $145.5 \mathrm{~kb}$ lambda DNA marker. This band represents the overlapping linear forms of pMP1046B and pLMP1046. In the untreated sample of JCM1046, the circular form of pMP1046B is retained in the well; therefore the $\operatorname{rep} B$ gene probe binds only to the well but not to the migrating linear plasmid pLMP1046 (Figure 2 panel B). However, in the S1-nuclease treated gDNA sample of JCM1046, the repB probe hybridised strongly to the overlapping pLMP1046/pMP1046B bands (Figure 2 panel $\mathrm{B}$ ), thereby confirming that the discrete replicons pLMP1046 and pMP1046B appear as one overlapping $120 \mathrm{~kb}$ band in their linear forms (Figure 2 panel B). The repB probe did not hybridise to the lanes containing JCM1047 or AH43348 gDNA, indicating that these strains lack a second repB-type circular megaplasmid (Figure 2 panel B). The presence of a second circular megaplasmid has also been reported in strains NIAS840 and SMXD51, both of these strains being of animal origin $[15,16]$.

Both S1-treated and untreated gDNA samples of JCM1046, JCM1047 and AH43348 show the presence of linear plasmids: pLMP1046 (140 kb), pLMP1047 $(140 \mathrm{~kb})$ and pLMP43348 (175 kb) respectively (Figure 2, panels $\mathrm{A}$ and $\mathrm{C})$. Each of the linear plasmids hybridised to a gene probe derived from the pLMP1046 sequence (Figure 2D). 


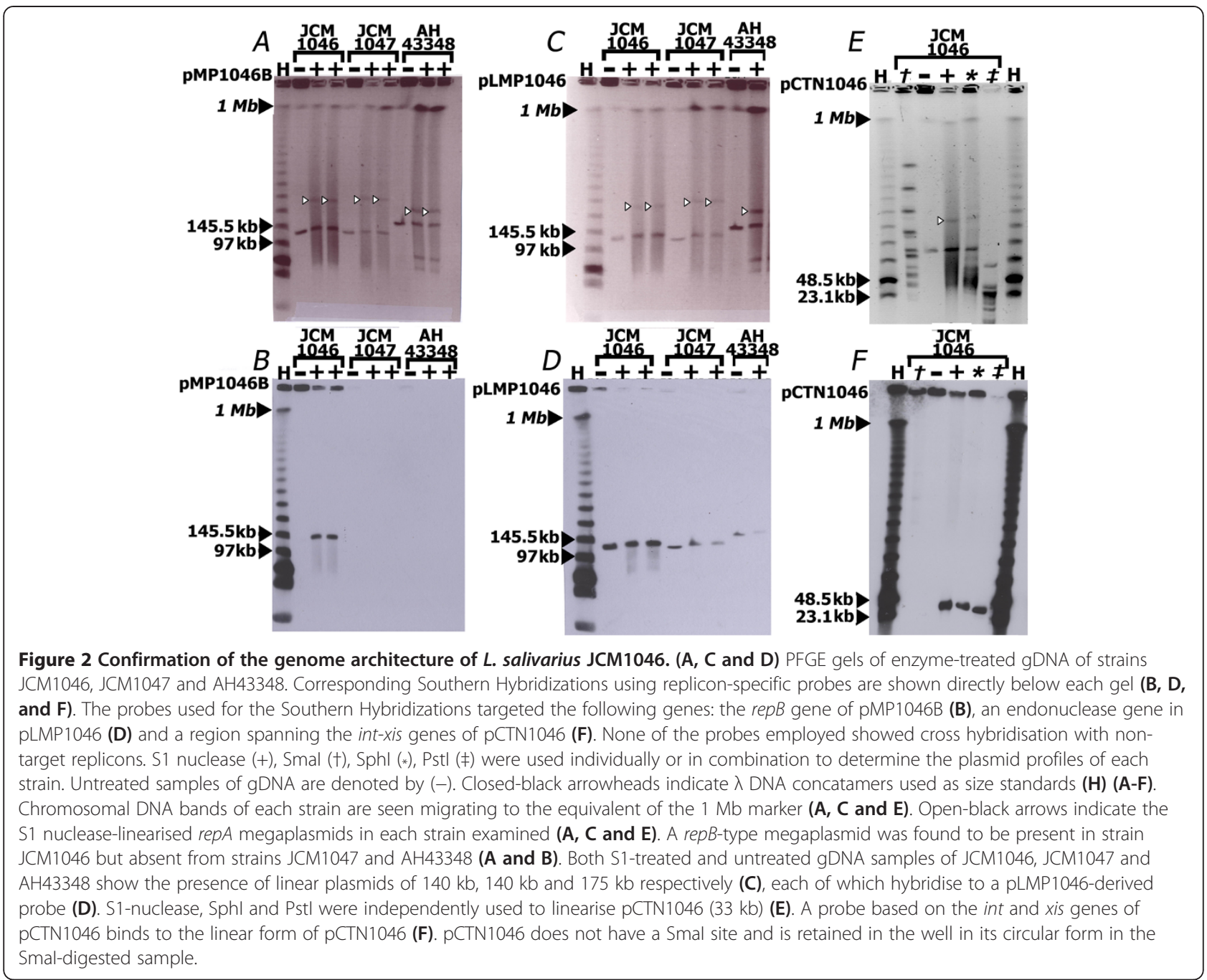

\section{A conjugative transposon in L. salivarius JCM1046}

We further identified a $33 \mathrm{~kb}$ plasmid in strain JCM1046 that was not previously observed in the plasmid profile of strain JCM1046 [12,40] and that was identified here by de novo scaffold assembly and designated pCTN1046. It harbours a Tn916-like element and was experimentally determined to have a circular topology. In silico analysis was first used to identify restriction enzymes whose use would resolve the chromosomal DNA of JCM1046 from that of pCTN1046. SphI and PstI each cut the chromosome multiple times, while linearising pCTN1046. Following treatment, pCTN1046 is visible as a band which migrates to a position between the $23.1 \mathrm{~kb}$ and $48.5 \mathrm{~kb}$, in keeping with the assembled $33 \mathrm{~kb}$ size of pCTN1046 (Figure 2E). The chromosome of JCM1046 has multiple SmaI restriction sites, while pCTN1046 has none. The multiple DNA bands in the SmaI-treated gDNA sample (Figure 2E) are chromosomal fragments, while the uncut circular form of pCTN1046 was retained in the well. A probe spanning the int and xis genes of pCTN1046 hybridised strongly to the $33 \mathrm{~kb}$ bands in the S1-nuclease, SphI and PstI treated samples of JCM1046 (Figure 2F). Similarly, the same probe hybridised to the circular form of pCTN1046 retained in the well of the SmaI-treated sample, but did not hybridise to the migrating chromosomal bands (Figure 2F). The same pattern of hybridisation was obtained when the experiment was repeated with a probe based on the tet $M$ gene harboured by pCTN1046 (data not shown). Although Tn916-like elements have been shown to insert at a single site in some species, in almost all bacterial hosts they insert at multiple sites [43]. Our data indicate that the conjugative transposon in strain JCM1046 is integrated at a single site in pCTN1046 and is absent from the rest of the genome.

\section{General genome features of L. salivarius JCM1046}

The unusual genome complexity of JCM1046 raised questions about gene distribution by replicon. Bioinformatic analysis identified 1,705 coding sequences in the 
chromosome, a coding density of $83.3 \%$ (Table 1). Biological functions could not be assigned to 360 of these protein coding sequences. The chromosome of $L$. salivarius JCM1046 contains 60 pseudogenes (Additional file 1). Seven rRNA operons were identified on the chromosome, as well as 76 tRNA genes for all 20 amino acids. The chromosome has an average GC content of 33.1\%, with three regions displaying atypical GC content relative to the rest of the genome (see below).

The largest of the plasmids pMP1046A has a coding density of $80.7 \%$. 214 coding sequences were identified, 79 of which were for hypothetical proteins. pMP1046A contains 15 pseudogenes (Additional file 1). The gene content of pMP1046A will be discussed in detail below.

We identified 159 coding regions in pMP1046B, though biological function could only be assigned to $29.7 \%$, the vast majority (110/158) of genes remaining cryptic. The GC\% content of pMP1046B (33.87\%) correlates well with the $33.1 \%$ GC content of the JCM1046 chromosome (Table 1) suggesting long-term adaptation to the host cell, or acquisition from a bacterium with a similar \% GC content. In addition to harbouring plasmidassociated replication machinery, pMP1046B harbours additional housekeeping and information-related genes, thus fulfilling the criteria for extrachromosomal elements known as chromids [44]. pMP1046B encodes two tRNA genes, tRNA (Gln) (LSI_3064) and tRNA (Ser) (LSJ_3066) but these genes are not uniquely present on pMP1046B i.e. they are paralogs of chromosomally encoded genes. Gene duplication can offer a level of genomic redundancy to a strain that is adapting to a new environment [45], and the tRNA genes encoded by pMP1046B may enable JCM1046 to respond more rapidly to changing environmental conditions. pLMP1046 harbours 112 coding sequences, none of which were pseudogenes. However, 85 of the predicted coding sequence products were annotated as hypothetical proteins, some of which may represent remnants of functional genes. The average GC content of pLMP1046 (30.9\%) is significantly lower than that of the JCM1046 chromosome (33.1\%), implying these replicons experienced distinct evolutionary histories and that pLMP1046 may be a recent acquisition.

PFGE analysis predicted the size of pLMP1046 to be approximately $130 \mathrm{~kb}$ (this study), but sequencing revealed a replicon that was $102 \mathrm{~kb}$. It is reasonable to assume that this discrepancy and the lack of identifiable terminal inverted repeats (TIR) (discussed below) is an assembly artifact due to omission of the presumptive repeat sequences in the terminal regions of pLMP1046. The problems faced in the sequencing of the telomeres of linear elements are well recognised [46].

In keeping with the guidelines outlined by Roberts et al. [47] the novel conjugative transposon contained within pCTN1046 was designated Tn6224. In silico analysis predicted a coding density of $76 \%$ for pCTN1046. Thirtynine coding sequences were identified (Table 1), the majority of which (21/39) are linked to the integrated transposon. The sole pseudogene harboured by this replicon lies outside the Tn6224 region and shows similarity to nitroreductase family proteins. The plasmid backbone of pCTN1046 has an average GC content of 30.8\%, whereas Tn6224 has an average GC content of 38.6\%. Unsurprisingly, this suggests that Tn6224 was most likely acquired via horizontal gene transfer (HGT). Insertion of Tn916like elements is not random, with the insertion sites differing from species to species [38], but generally displaying a distinct preference for target sites which are A-T rich and that have a limited homology with the ends of the element [43]. As only one copy of Tn6224 was found in the genome of JCM1046, a putative consensus of the target sequence in L. salivarius could not be determined. Accounting for the potential presence of coupling sequences, the 35 bp that flanked either end of Tn6224 was examined to determine if the target sites in L. salivarius are in keeping with those generally described for these elements [38]. The AT content of the sequences upstream and downstream of Tn6224 were found to be $97.1 \%$ and $85.7 \%$ respectively, indicating that the target site for Tn6224 is likely to be similar to those of other species [38].

\section{Phage, transposases and CRISPR regions}

PHAST [48] identified two regions of bacteriophage-related DNA in the genome of JCM1046, both found on the chromosome of JCM1046. In addition to a $22.6 \mathrm{~kb}$ remnant prophage that spans residues $1378015-1400296 \mathrm{bp}$, an intact $28,541 \mathrm{~kb}$ prophage was also identified on the chromosome which spans residues $1439831-1444300 \mathrm{bp}$. At $43.7 \%$, the remnant prophage is one of the three regions of atypical GC content.

102 transposases (including 22 pseudogenes), representing eight IS families were found distributed across four of the five replicons of strain JCM1046. The distribution of transposases is detailed in Additional file 2.

Clusters of regularly interspersed short palindromic repeats (CRISPRs) and CRISPR-associated genes (cas genes) provide the host with acquired and heritable resistance against genetic transformation, phage and plasmid proliferation [49]. One CRISPR associated system (cas) was identified on the chromosome of JCM1046 at position 810173-812140 bp, consisting of a 1059 bp repeat locus composed of a $36 \mathrm{bp}$ direct repeat and 26 spacers. This CRISPR region is immediately upstream of the gene encoding Cas2 and immediately downstream of eight additional CRISPR-associated protein coding genes.

\section{Replication of extrachromosomal elements}

The replication region of pMP1046A extends from LSJ_ 2000 to LSJ_2006 (6449 bp). The gene content and 
organisation of the replication region of pMP1046A is highly similar to (98\% nt identity (ID)) that of pMP118 [9] and to those of other sequenced L. salivarius strains (Figure 3). pMP1046A is likely to replicate by theta-form replication [50].

The predicted replication region of pMP1046B spans residues $128175-1974 \mathrm{bp}$ of the plasmid. This region includes a repA gene (LSJ_3160) at the position of a switch in GC skew that is characteristic of replication origins [52]. LSJ_3160 shares $36-56 \%$ aa ID with L. salivarius RepA protein sequences. The RepA protein of pMP1046B also displays $40 \%$ aa ID to the RepA protein of the pig isolate Lactobacillus reuteri ATCC 53608 [53]. The second gene in the pMP1046B ori region, LSJ_3000 encodes a predicted partitioning/copy control protein, RepB.

Analysis of pLMP1046 indicates that it shares limited sequence homology or gene synteny with linear replicons of other species. However, given the lack of sequenced counterparts in other lactobacilli, the absence of homologous genes in databases is unsurprising. Replication is commonly initiated from one or more internal ori sites in linear plasmids and proceeds bidirectionally towards the telomeres [54-56]. Our previous study indicated that the linear plasmids of $L$. salivarius did not harbour the repA and repE genes encoded by the circular repA-type megaplasmids of L. salivarius [12], and thus it was presumed that pLMP1046 utilised an alternate mode of replication to the circular plasmids of L. salivarius [12]. Sequence analysis identified two plasmid-associated replication genes encoded by pLMP1046, LSJ_4017 (nt 25084-26103) and LSJ_4096 (nt 89781-91007). LSJ_4017 exhibits 39$41 \%$ aa ID with proteins annotated as either RepE or RepA in the circular megaplasmids of $L$. salivarius. This level of sequence homology was not high enough to cause cross hybridisation between the replication genes of pMP118 and the $r e p A / E$ gene identified in pLMP1046, thus

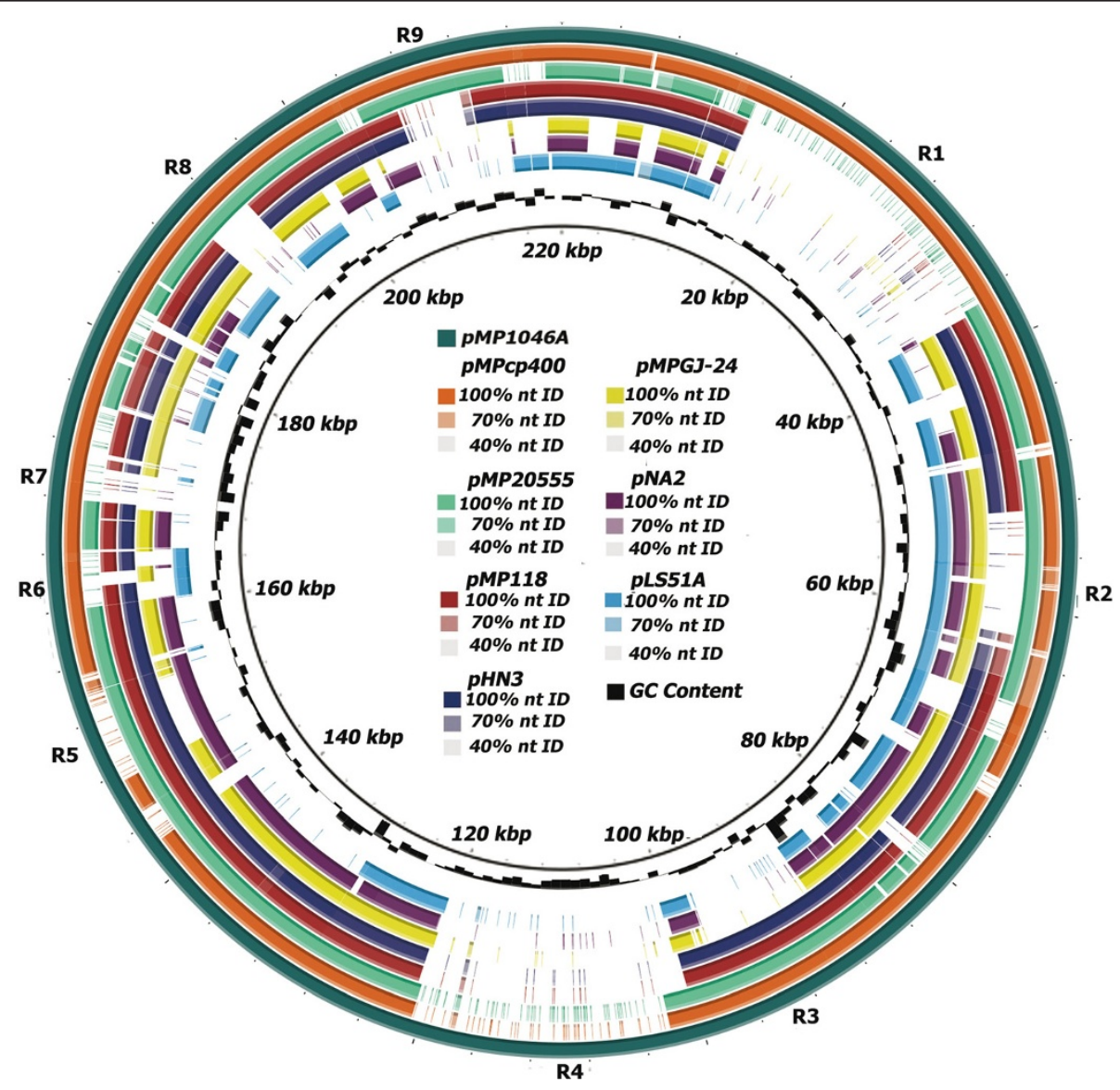

Figure 3 A comparison eight repA-type megaplasmids of $L$. salivarius. A BLAST atlas diagram of eight repA-type megaplasmids of $L$. salivarius was generated using BLAST Ring Image Generator (BRIG) [51], using pMP1046A as the reference replicon (the outer dark green ring). Working inwards from pMP1046A, the next seven rings represent query repA-type plasmids of L. salivarius strains: cp400, pMP20555, pMP118, pHN3, pMPGJ-24, pNA2, pLS51A. When the completed or circularised version of the repA-type megaplasmid was not available (L. salivarius cp400 [18] and L. salivarius DSM20555), all available sequence data for each strain was mapped to pMP1046A. Regions of diversity between the repA-type megaplasmids are indicated by the labels R1-R9. The GC\% of pMP1046A was projected onto the mapped plasmid sequences (black ring) and sits outside the molecular clock surrounding the figure legend at the centre of the figure. 
accounting for the observations of our previous study [12]. LSJ_4096 encodes a putative RepB-like replication initiator protein. The replication origins of Streptomyces linear plasmids are comprised of helicase-like rep genes and interons [22], while the replication ori of N15 is located within the rep $A$ gene, which acts as a multifunctional protein combining primase, helicase and originbinding activities [57]. RepA boxes were not identified in the proximity of either the rep $A$ or repB genes of pLMP1046; however, the genomic region immediately upstream of the repA coincides with a switch in GC skew. This suggests that the repA gene lies within the putative ori region of pLMP1046.

The mechanism that pLMP1046 uses to prevent the progressive shortening of their telomeres after each cycle of replication is unknown. It is possible it employs a circular mode, as in some Streptomyces linear plasmids [58], but it is more plausible that the sequence of pLMP1046 is missing sections of its terminal regions due to a sequencing or assembly artefact. Further analysis of the terminal regions of pLMP1046 will be required to fully elucidate the mechanism involved in the replication of $L$. salivarius linear plasmids.

There are two replication associated genes harboured by the plasmid backbone of pCTN1046 which are separated by approximately $6 \mathrm{~kb}$. LSJ_5030c shares 52\% aa ID with a replication-associated protein in Lactobacillus amylovorus GRL 1112. LSJ_5035c encodes the plasmid associated replication protein, RepB, the gene for which coincides with the position of a switch in GC skew, and is therefore the presumed to be the replication origin of pCTN1046. LSJ_5035c shares 36\% aa ID with the RepB protein of L. lactis subsp. cremoris TIFN1 and $100 \%$ aa ID to a replication initiation protein in the $30.6 \mathrm{~kb}$ plasmid pLS51C in L. salivarius SMXD51.

\section{Plasmid maintenance}

Several of the JCM1046 plasmids encode genes implicated in plasmid incompatibility. Three of the plasmids (pMP1046B, pLMP1046 and pCTN1046) encode a repBlike gene, two (pMP1046A and pMP1046B) encode repElike genes and two (pMP1046A and pLMP1046) encode repA-like genes. However the presumptive replication regions of the co-resident plasmids display low levels of sequence ID with the highest nt ID shared between the repB genes of pLMP1046 and pCTN1046 at 58.7\%. The mosaic nature of the replication regions as well as the lack of nucleotide homology between the respective replication associated genes of the co-resident plasmids is a plausible explanation for the compatibility of the plasmids that co-exist in strain JCM1046. Several complete ToxinAntitoxin (TA) systems were identified on plasmids pMP1046A and pLMP1046 and likely play a role in the stability and maintenance of the co-resident plasmids in JCM1046.

\section{Comparative $L$. salivarius genomics and relationship to phenotype \\ Chromosome}

In contrast to the human probiotic strains $L$. salivarius UCC118 and L. salivarius CECT 5713 which share 98.5\% nt pairwise ID between their chromosomes and 98.6\% nt pairwise ID between their repA-type megaplasmids, the genome structure, and sequence of JCM1046 diverges significantly from the other published L. salivarius strains.

The chromosome of JCM1046 shares $68.4 \%$ nt pairwise ID with strain UCC118 and includes 55 regions (min $800 \mathrm{bp}$ ) [59], representing $16.5 \%$ of the chromosome, that are absent from strain UCC118 (Additional file 3). Indeed, a comparison of the chromosome of strain JCM1046 to that of the other published L. salivarius genome sequences revealed 48 chromosomally encoded genes in JCM1046 that were absent in the other published $L$. salivarius genomes (Additional file 4). These genes primarily belong to categories of genes that have been shown to be hypervariable among L. salivarius strains [7] and other Lactobacillus species [60] and include transposases, phage-associated genes, and genes involved in carbohydrate metabolism and host interaction (Additional file 4). The GC\% map of the JCM1046 chromosome identifies three regions with significantly deviating GC content, one of which is the remnant prophage that is resident on the chromosome. The smallest of these regions stretches from residues 782,449 to $793,883 \mathrm{bp}$. This $11.4 \mathrm{~kb}$ region has a GC\% content of $43.6 \%$ and encodes a protein containing a mucin-binding MucBP domain (LSJ_0784), several transposases, hypothetical proteins and a choloylglycine hydrolase (BSH2, LSJ_0788). Although present in the porcine strains JCM1046 and cp400, this region is absent from other sequenced genomes of $L$. salivarius and may represent a niche specific adaptation.

$\mathrm{BSH} 2$ is one of two choloylglycine hydrolase genes encoded by the genome of JCM1046 [11]; the second (BSH1, LSJ_2111) is present on pMP1046A and is widespread among L. salivarius strains [11]. In contrast, BSH2 has only been identified in three isolates to date, JCM1046, LMG14476 and cp400, all of which are of animal origins. BSH2 confers JCM1046 with an ability to resist much higher concentrations of the major human conjugated bile acids when compared to strains that harbour BSH1 alone [11]. In addition, BSH2 has recently been shown to reduce weight gain and serum LDL cholesterol and liver triglycerides in mice fed normal or high-fat diets [61].

We have previously shown that exopolysaccharide (EPS) production levels and the presence of associated 
genes vary widely in L. salivarius [7]. JCM1046 harbours a single EPS gene cluster that spans $33 \mathrm{~kb}$, containing 33 genes, including two pseudogenes (Additional file 5). The EPS locus exhibits an atypical GC content relative to the rest of the chromosome, $29.7 \%$ and $33.1 \%$ respectively.

\section{pMP1046A}

Nine substantial regions of sequence diversity, ranging in size from 3.8-22.6 kb were identified between pMP1046A and the sequences of the other published repA-type megaplasmids (Figure 3; Table 2). Hypothetical proteins and transposases are abundant within these regions (Table 2). Indeed, region two and region four primarily harbour hypothetical proteins, while region six harbours only IS elements (Table 2, R2, R4 and R6). Regions three and eight mostly encode solute transporters (Table $2 \mathrm{R} 3$ and R8).

The largest region of diversity among the strains examined is $22.6 \mathrm{~kb}$ (Figure 3, R1) and harbours several genes predicted to work synergistically with chromosomally encoded pathways to broaden the metabolic capabilities of strain JCM1046. Although present in strain cp400, this region is highly divergent in all other examined plasmids (Figure 3) and primarily encodes proteins involved in aa metabolism. JCM1046 is prototrophic for Lproline due to the presence of a chromosomally-encoded pathway. Three paralogous genes (LSI_2016, LSJ_2020 and LSI_2021) in this region are responsible for the interconversion of L-proline to D-proline. Also present in this region are two genes (LSJ_2031, selD and LSJ_2028, selA) which work in conjunction with the chromosomally encode gene (LSI_0220, serS) to synthesise L-selenocysteine. These increased biosynthetic capabilities are likely to enhance the ability of JCM1046 to thrive in the competitive porcine GIT.

The genes present in regions five and nine (Table 2) are primarily involved in the metabolism and transport of carbohydrates, and vary from strain to strain (Figure 3, R5 and R9). Similarly to pMP118, pMP1046A harbours both single copy and paralogous genes that complete a number of the carbohydrate fermentative pathways that are partially encoded by the chromosome of JCM1046A. These include the pentose phosphate and gluconeogenesis pathways as well as the fermentation pathways for sorbitol and rhamnose.

Bacteriocin production is a putative probiotic trait of L. salivarius strains (see review [62]). The genetic organisation of the $7.9 \mathrm{~kb}$ bacteriocin locus in pMP1046A is analogous to that of the Abp118 locus in the human isolate UCC118 (Figure 3 R7). The structural genes (LSJ_2170 and LSJ_2169) of the bacteriocin locus of pMP1046A, are identical to the genes (Sln1 and $S \ln 2$ ) which are responsible for the production of the twocomponent antilisterial bacteriocin Salivaricin P. This bacteriocin differs in sequence to Abp118 by two amino acids [63] and is produced by several other porcine isolates of $L$. salivarius $[63,64]$. However, a frame-shift in the $a b p T$ gene (LSI_2163) of JCM1046 is likely responsible for the bacteriocin negative phenotype observed in this strain [12].

\section{pCTN1046}

The conjugative element Tn6224 harboured by plasmid pCTN1046 shares $96.2 \%$ nt sequence ID with the conjugative element Tn916 and lacks only two genes which encode hypothetical proteins in the conjugative region of Tn916. When comparing pCTN1046 to other sequenced L. salivarius genomes, pCTN1046 shares $64.6 \%$ nt ID with the $30.4 \mathrm{~kb}$ plasmid pLS51C harboured by the probiotic avian isolate SMDX51 [16]. This plasmid shares sequence homology with both the plasmid backbone and conjugative element of pCTN1046 (Figure 4). Tn6224 appears to be functionally intact, containing the: conjugative, recombination, transcriptional regulation and accessory genes (Additional file 6) associated with Tn916. In contrast the integrated conjugative element that is resident in pSL51C appears to be a remnant of a conjugative element as it lacks the recombination genes xis (LSJ_5019) and int (LSJ_5020). pLS51C harbours a limited number of the conjugative genes present in Tn6224 and Tn916 but lacks the $\operatorname{ard} A$ gene present in pCTN1046 which has been recently shown to aid the transfer of mobile genetic elements (MGEs) between unrelated bacterial species [65]. A putative TnGBS1-like element (TnLsal1.1) was identified in L. salivarius strain DSM20555. However, our analysis suggests that the contig predicted to harbour TnLsal1.1 [66] forms part of the putative pMP20555 megaplasmid in the type-strain L. salivarius DSM20555. The weak homology between the proteins identified in TnLsal1.1 and those identified in other TnGBS1-like elements [66] may be due to their similar functional roles in their respective replicons.

L. salivarius strains are increasingly being examined for their probiotic properties in both humans and animals [5]. Dissemination of antibiotic resistance genes via the food chain to either the resident microbiota of the human gut or pathogenic bacteria is likely to have far reaching effects on both human and animal health and present a major financial cost [67]. Thus, the identification of conjugative transposons carrying antibiotic resistance genes in the genomes of two animal isolates of $L$. salivarius may have repercussions for strain selection in future probiotic studies.

\section{pMP1046B and pLMP1046}

Plasmids pMP1046B and pLMP1046 share neither sequence homology nor gene synteny with the additional L. salivarius plasmids sequenced to date. Both of these replicons require further functional characterisation to 
Table 2 Regions of sequence diversity in pMP1046A

\begin{tabular}{|c|c|c|c|c|}
\hline $\begin{array}{l}\text { Region of diversity: base } \\
\text { coordinates (size } b p \text { ) }\end{array}$ & Gene & Start position & End position & Gene product \\
\hline \multirow[t]{23}{*}{ R1: $14543 . .37152$ (22609) } & LSJ_2012 & 14616 & 15683 & Hypothetical membrane protein \\
\hline & LSJ_2013 & 15827 & 16882 & Hypothetical membrane protein \\
\hline & LSJ_2014 & 17072 & 17242 & Conserved hypothetical protein \\
\hline & LSJ_2015 & 17257 & 18330 & Putative thiosulfate sulfurtransferase \\
\hline & LSJ_2016 & 18782 & 20686 & D-proline reductase, prdA \\
\hline & LSJ_2017 & 20688 & 21005 & Conserved hypothetical protein \\
\hline & LSJ_2018 (P) & 20995 & 21720 & Proline reductase, probable pseudogene \\
\hline & LSJ_2019 & 21740 & 22480 & Conserved hypothetical protein \\
\hline & LSJ_2020 & 22501 & 22974 & D-proline reductase \\
\hline & LSJ_2021 & 22999 & 24018 & Proline racemase \\
\hline & LSJ_2022 & 24031 & 24909 & Hypothetical membrane protein \\
\hline & LSJ_2023 & 25005 & 26603 & Amino acid permease \\
\hline & LSJ_2024 & 26684 & 27322 & Conserved hypothetical protein \\
\hline & LSJ_2025 & 27434 & 27691 & Conserved hypothetical protein \\
\hline & LSJ_2026 & 27691 & 29583 & Selenocysteine-specific elongation factor \\
\hline & LSJ_2027 & 29573 & 30712 & Cysteine desulfurase \\
\hline & LSJ_2028 & 30713 & 32113 & L-seryl-tRNA selenium transferase, selA \\
\hline & LSJ_2029 & 32119 & 32448 & Conserved hypothetical protein \\
\hline & LSJ_2030 & 32560 & 33870 & NADH dehydrogenase \\
\hline & LSJ_2031 & 33963 & 34937 & Selenophosphate synthase, selD \\
\hline & LSJ_2032 & 35037 & 36209 & Hypothetical membrane protein \\
\hline & LSJ_2033 & 36228 & 36473 & Conserved hypothetical protein \\
\hline & LSJ_2034 & 36698 & 37129 & Conserved hypothetical protein \\
\hline \multirow[t]{7}{*}{ R2: $52540 . .64667$ (12127) } & LSJ_2049 & 52523 & 54520 & Conserved hypothetical protein \\
\hline & LSJ_2050 & 54507 & 55370 & Conserved hypothetical protein \\
\hline & LSJ_2051 & 55360 & 56145 & Conserved hypothetical protein \\
\hline & LSJ_2052 & 56204 & 58906 & DNA methylase \\
\hline & LSJ_2053 & 58913 & 60871 & DEAD/DEAH box helicase family protein \\
\hline & LSJ_2054 & 60864 & 62066 & Conserved hypothetical protein \\
\hline & LSJ_2055 & 62137 & 64662 & Conserved hypothetical protein \\
\hline \multirow[t]{9}{*}{ R3: 88322..98017 (9695) } & LSJ_2078 (P) & 88463 & 88739 & Transposase, probable pseudogene \\
\hline & LSJ_2079 & 88814 & 89641 & Transposase ISLasa15, IS3 family \\
\hline & LSJ_2080 & 90080 & 91279 & MFS Transport protein \\
\hline & LSJ_2081 & 91593 & 92813 & MFS Transport protein \\
\hline & LSJ_2082 & 92865 & 93761 & Transcriptional regulators, LysR family \\
\hline & LSJ_2083 & 93920 & 94756 & Conserved hypothetical protein \\
\hline & LSJ_2084 & 94785 & 95612 & 2-deoxy-D-gluconate 3-dehydrogenase \\
\hline & LSJ_2085 & 95631 & 97346 & Fumarate reductase flavoprotein subunit \\
\hline & LSJ_2086 & 97367 & 98242 & Shikimate 5-dehydrogenase \\
\hline \multirow[t]{4}{*}{ R4: $100291 . .121050$ (20759) } & LSJ_2089 & 100815 & 101621 & Conserved hypothetical protein \\
\hline & LSJ_2090 & 101614 & 101832 & Hypothetical protein \\
\hline & LSJ_2091 & 102071 & 102190 & Hypothetical protein \\
\hline & LSJ_2092 & 102310 & 103761 & Plasmid replication protein-primase \\
\hline
\end{tabular}


Table 2 Regions of sequence diversity in pMP1046A (Continued)

\begin{tabular}{|c|c|c|c|c|}
\hline & LSJ_2093 & 103865 & 104446 & Hypothetical membrane protein \\
\hline & LSJ_2094 & 104468 & 104620 & Hypothetical membrane protein \\
\hline & LSJ_2095 & 104818 & 105573 & Hypothetical protein \\
\hline & LSJ_2096 & 105746 & 106198 & Hypothetical secreted protein \\
\hline & LSJ_2097 & 106590 & 106853 & Hypothetical protein \\
\hline & LSJ_2098 & 106973 & 107965 & Conserved hypothetical protein \\
\hline & LSJ_2099 & 108439 & 108663 & Hypothetical secreted protein, possible signal peptide \\
\hline & LSJ_2100 & 109441 & 110277 & Hypothetical protein \\
\hline & LSJ_2101 & 110287 & 111057 & Putative DNA-entry nuclease \\
\hline & LSJ_2102 & 111064 & 111543 & Conserved hypothetical protein \\
\hline & LSJ_2103 & 111576 & 111743 & Hypothetical secreted protein \\
\hline & LSJ_2104 & 111993 & 112103 & Hypothetical protein \\
\hline & LSJ_2105 & 112160 & 112756 & Conserved hypothetical protein \\
\hline & LSJ_2106 & 112749 & 115094 & Conserved hypothetical protein \\
\hline & LSJ_2107 & 115914 & 118892 & Hypothetical protein \\
\hline & LSJ_2108 & 119031 & 120428 & Conserved hypothetical protein \\
\hline & LSJ_2109 & 120839 & 121078 & Hypothetical protein \\
\hline \multirow[t]{7}{*}{ R5: $147401 . .153337$ (5936) } & LSJ_2136c & 147401 & 148081 & Fructose-6-phosphate aldolase \\
\hline & LSJ_2137c & 148148 & 148528 & PTS system, glucitol/sorbitol-specific IIA component \\
\hline & LSJ_2138c & 148565 & 149590 & PTS system, glucitol/sorbitol-specific IIBC component \\
\hline & LSJ_2139c & 149607 & 150149 & PTS system, glucitol/sorbitol-specific IIC2 component \\
\hline & LSJ_2140C & 150161 & 150658 & Sorbitol operon activator \\
\hline & LSJ_2141C & 150659 & 152518 & Sorbitol operon transcription regulator \\
\hline & LSJ_2142C & 152534 & 153337 & Sorbitol-6-phosphate 2-dehydrogenase \\
\hline \multirow[t]{4}{*}{ R6: $160003 . .164289$ (4286) } & LSJ_2150 & 160058 & 160575 & Transposase ISLasa1a, IS1223 family \\
\hline & LSJ_2151 & 160607 & 161473 & IS1223 family transposase \\
\hline & LSJ_2152 & 161537 & 162544 & Transposase fragment \\
\hline & LSJ_2153 & 162694 & 163983 & ISL3 family transposase \\
\hline \multirow[t]{16}{*}{ R7: 167503..182637 (15134) } & LSJ_2155 & 166716 & 167537 & Integrase \\
\hline & LSJ_2156 & 167573 & 167839 & Hypothetical protein \\
\hline & LSJ_2157 & 168343 & 169011 & Hypothetical protein \\
\hline & LSJ_2158 & 169087 & 169419 & Hypothetical protein \\
\hline & LSJ_2159 & 169424 & 170053 & Conserved hypothetical protein \\
\hline & LSJ_2160 & 170398 & 170802 & Toxin antitoxin system, toxin component \\
\hline & LSJ_2161 & 170802 & 171023 & Toxin antitoxin system, antitoxin component \\
\hline & LSJ_2162 & 171466 & 172614 & AbpD bacteriocin export accessory protein \\
\hline & LSJ_2163 (P) & 1172630 & 174788 & $\begin{array}{l}\text { AbpT bacteriocin export accessory protein, probable } \\
\text { pseudogene due to frameshift }\end{array}$ \\
\hline & LSJ_2164 & 175441 & 175680 & Hypothetical membrane spanning protein \\
\hline & LSJ_2165 & 175717 & 176511 & AbpR response regulator \\
\hline & LSJ_2166 & 176525 & 177817 & AbpK sensory Transduction Histidine Kinase \\
\hline & LSJ_2167 & 177819 & 177938 & AbplP induction peptide \\
\hline & LSJ_2168 (P) & 178086 & 178232 & AbplM bacteriocin immunity protein \\
\hline & LSJ_2169 & 178371 & 178577 & Abp118 bacteriocin beta peptide \\
\hline & LSJ_2170 & 178595 & 178789 & Abp118 bacteriocin alpha peptide \\
\hline
\end{tabular}


Table 2 Regions of sequence diversity in pMP1046A (Continued)

\begin{tabular}{|c|c|c|c|c|}
\hline & LSJ_2171 & 178795 & 179052 & Bacteriocin-like prepeptide \\
\hline & LSJ_2172 & 179182 & 179355 & Nonfunctional salvaricin B precursor \\
\hline & LSJ_2173 & 179588 & 179851 & Hypothetical membrane spanning protein \\
\hline & LSJ_2174 & 179890 & 180219 & Hypothetical protein \\
\hline & LSJ_2175 & 180441 & 181415 & Hypothetical membrane associated protein \\
\hline & LSJ_2176 (P) & 1181578 & 182227 & HAD-superfamily hydrolase, probable pseudogene due to frameshift \\
\hline & LSJ_2177 & 182338 & 182679 & Hypothetical protein \\
\hline \multirow[t]{3}{*}{ R8: $189782 . .193560$ (3778) } & LSJ_2187 & 189909 & 191414 & Sodium solute symporter \\
\hline & LSJ_2188 & 191432 & 192556 & $\mathrm{Na}(+) / \mathrm{H}(+)$ antiporter \\
\hline & LSJ_2189 & 192623 & 193354 & Xylose isomerase domain protein \\
\hline \multirow[t]{9}{*}{ R9: 204232..215364 (11132) } & LSJ_2201 & 204295 & 206286 & Transketolase \\
\hline & LSJ_2202 & 206304 & 206957 & Transaldolase \\
\hline & LSJ_2203 & 207466 & 208521 & L-iditol 2-dehydrogenase \\
\hline & LSJ_2204 & 208562 & 209611 & Alcohol dehydrogenase \\
\hline & LSJ_2205 & 209625 & 210896 & Galacitol PTS, EIIC \\
\hline & LSJ_2206 & 210923 & 211219 & Galactitol PTS, EIIB \\
\hline & LSJ_2207 & 211254 & 211706 & Galacitol PTS, EIIA \\
\hline & LSJ_2208 & 211888 & 212688 & DeoR family transcriptional regulator \\
\hline & LSJ_2209 & 212812 & 215178 & Xylulose-5-phosphate/fructose-6-phosphate phosphoketolase \\
\hline
\end{tabular}

Genes associated with the regions of diversity (R1-R9) in pMP1046A, as illustrated in Figure 3. Genes present on the reverse strand are denoted by the suffix c following the locus tag (LSJ_XXX). Pseudogenes are denoted by (P). Numbers in italics represents the size of the region in bp.

determine whether or not they have an impact on the phenotype and ecological properties of JCM1046.

\section{Conclusion}

The porcine strain JCM1046 harbours the most structurally complex multipartite genome identified in L. salivarius to date. Through complete sequencing and assembly of the genome of JCM1046 we identified two additional replicons that were not previously known to form part of the plasmid complement of this strain, and that would probably not have been identified by the high-coverage draft genome sequencing commonly applied. We determined that one of these replicons, pMP1046B is a candidate chromid, though much of its gene function remains cryptic. The plasmids of $L$. salivarius probably confer on their host many of the genes associated with niche adaptation and which are known to modulate the phenotype of a strain significantly. JCM1046 was found to harbour

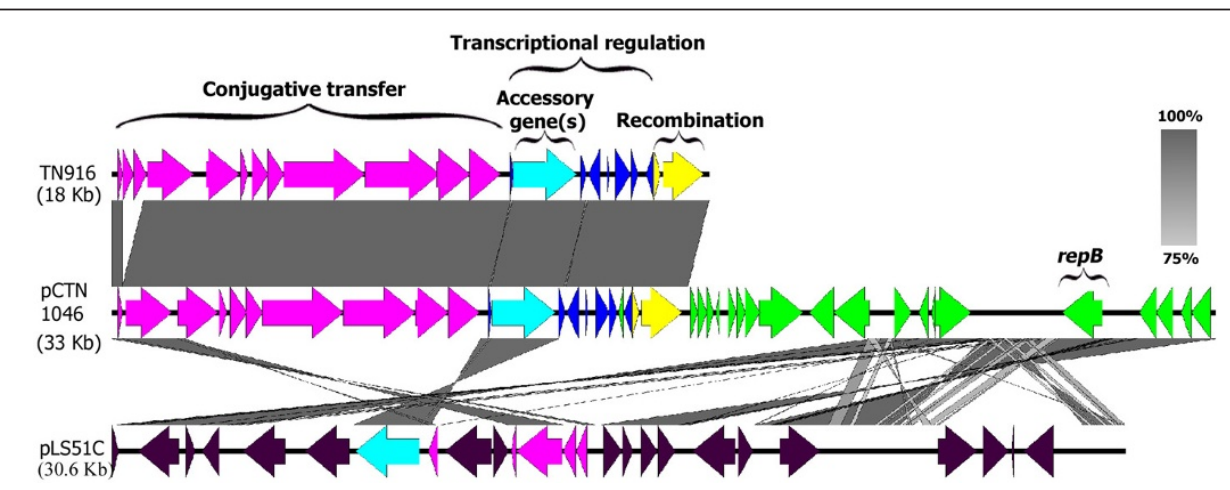

Figure 4 Sequence alignment of Tn916, pCTN1046 and pLS51C. A linear comparison of the BLASTN matches between the extrachromosomal replicons pCTN1046 and pLS51C (harboured by L. salivarius strain SMXD51 [16]) and the conjugative transposon Tn916. Vertical grey-coloured blocks between sequences indicate regions of shared $\mathrm{nt}$ ID. The gradient of the grey colour corresponds to the percentage of shared nt ID (dark grey (100\%)-light grey (75\%)). The genes in each element are coloured according to their function in the conjugative transposon Tn916: pink (conjugative transfer), turquoise (accessory genes and transcriptional regulation), dark blue (transcriptional regulation) and yellow (recombination). Genes encoded by the plasmid backbone of pCTN1046 are green, and those associated with the backbone of pLS51C are dark purple. 
both plasmid-encoded (pMP1046A) and chromosomally encoded genes associated with adaptation to the GIT environment. The putative replication ori of pLMP1046 was identified and the sequence of this linear plasmid will provide a genetic platform for the study of linear DNA replication in Lactobacillus sp. An integrated conjugative transposon (Tn6224), carrying tetracycline resistance was identified in plasmid pCTN1046, the first described in a sequenced $L$. salivarius genome. It will be interesting to see how prevalent Tn6224-like elements are within the $L$. salivarius population, as more genome sequences become available.

\section{Methods}

\section{Bacterial strains and culture conditions}

L. salivarius strains were routinely cultured at $37^{\circ} \mathrm{C}$ under micro-aerophilic conditions $\left(5 \% \mathrm{CO}_{2}\right)$ in de ManRogosa-Sharpe (MRS) medium (Oxoid Ltd, Basingstoke, Hampshire, UK).

\section{PFGE plug preparations}

Agarose gel plugs of high molecular weight DNA for PFGE were prepared according to a published protocol [12].

\section{S1-nuclease treatment}

Single slices $(2 \mathrm{~mm} \times 2 \mathrm{~mm})$ were treated with Aspergillus oryzae S1 nuclease (Roche, Mannheim, Germany) according to a published protocol [12].

\section{Restriction of PFGE plugs}

Single slices $(2 \mathrm{~mm} \times 2 \mathrm{~mm})$ were washed three times for $15 \mathrm{~min}$ in $1 \mathrm{ml} 10 \mathrm{mM}$ Tris.Cl, $0.1 \mathrm{mM}$ EDTA (pH 8.0) at room temperature. Each slice was pre-incubated with $250 \mu \mathrm{l}$ of restriction buffer recommended for the enzyme for $30 \mathrm{~min}$ at $4^{\circ} \mathrm{C}$ and then replaced with $250 \mu \mathrm{l}$ of fresh buffer containing 20 units of restriction enzyme. Restriction digests were carried out overnight at temperatures recommended by the supplier.

\section{Pulsed field gel electrophoresis}

Treated (S1-nuclease/restriction enzyme) and untreated plugs of genomic DNA were examined under conditions employed in a previously published protocol [12]. Gels were stained in distilled water containing $0.5 \mu \mathrm{g} / \mathrm{ml}$ ethidium bromide for $60 \mathrm{~min}$ in light-limited conditions and destained in water for $30 \mathrm{~min}$.

\section{Probe preparation and Southern hybridization}

Probe preparations and Southern blot hybridizations were carried out according to a published protocol [12]. The primers used to generate PCR amplicons that were used as probes are listed in Additional file 7.

\section{Genome sequencing}

L. salivarius genomic DNA (gDNA) isolation was performed as described previously [1]. The genome of JCM1046 genome was sequenced using a combination of shotgun sequencing by the Sanger method (4-fold coverage), pyrosequencing (24-fold coverage) and Illumina (204-fold coverage). A large-insert ( $40 \mathrm{~kb})$ fosmid library was constructed in the CopyControl ${ }^{\mathrm{Tm}}$ pCCFOS $^{\mathrm{max}}$ vector system (Epicentre Technologies, USA).Corporation, USA) Insert ends $(\sim 800 \mathrm{bp} / \mathrm{read})$ were sequenced generating mate pairs and $7.5 \mathrm{Mb}$ sequencing data. Pyrosequencing generated approximately 217,000 unpaired reads $(\sim 250 \mathrm{nt})$; from a half plate on a 454 FLX instrument (Agencourt Biosciences, Beverly, MA). In addition to the shotgun and 454 data for the JCM1046 genome, an additional half lane of Illumina sequencing (23 Mb total sequence data) was obtained which consisted of a $3 \mathrm{~kb}$ mate-pair library and a 400 bp paired-end library (Fasteris, Geneva, Switzerland). Each Illumina library provided an average of 204-fold coverage. Illumina reads were assembled (default settings) into contigs using Velvet v 0.7 [68], which were then used to generate $300 \mathrm{bp}$ pseudocontigs. A de novo genome assembly of the shotgun, 454 and Illumina (pseudocontigs) sequence data was performed using the Roche/454 Life Sciences Newbler (Gs) assembler v 2.3 [69], producing an initial assembly of 102 contigs (>500 bp) distributed over 32 scaffolds for the genome of JCM1046. The resulting 454 assembly was then used as a reference for the mapping of raw Illumina data. This mapping assembly was performed using Mira [70] and undertaken to extend contigs, close gaps and for error correction of the draft genome. Gap closure was achieved using a PCR-based strategy. Primers were designed at the end of contigs and Dreamtaq DNA polymerase (Fermentas, Ontario, Canada) was used to amplify products corresponding to contig-contig gaps. Scaffolds were ordered and oriented by PCR using primers were designed at the ends of the scaffolds and the inter-scaffold region was amplified using Extensor long PCR enzyme mix (Abgene, Epsom, UK). PCR products for both the sequencing gaps and the inter-scaffold gaps were sequenced by Eurofins MWG Operon (Ebersberg, Germany) and the sequences were integrated into the assembly using PHRAP [71]. Correct placement of the gap sequences was confirmed by observation using Tablet, a next generation sequencing graphical viewer [72].

\section{Genome annotation}

Annotation was carried out according to a published protocol [73] with minor modifications. Specifically, initial annotation was transferred from the related strain $L$. salivarius UCC118 [74] and then manually curated in Artemis [75]. PHAST [48] was used to identify prophage regions within the genome sequence. 


\section{Data availability}

The annotated genome sequence has been deposited in GenBank under accession numbers CP007646 (chromosome), CP007647 (pMP1046A), CP007648 (pMP1046B), CP007649 (pLMP1046), CP007650 (pCTN1046).

\section{Genome comparisons}

Nucleotide alignments were generated using a local BLAST v 2.2.22 installation which were then visualized and analyzed for gene conservation and sequence synteny using the Artemis Comparison Tool (ACT) [76].

\section{Identification of novel genetic regions}

The Novel Region Finder module of Pan seq v 2.0 [59] was used to identify novel genomic regions in strain JCM1046, compared to other L. salivarius genome sequences. A minimum novel region size of 800 bp was chosen and default Nucmer values were used.

\section{Additional files}

\section{Additional file 1: Pseudogenes in the L. salivarius JCM1046}

genome. Pseudogenes were characterized as such due to the presence of in-sequence frame-shifts, deletions, or interruptions of the gene by insertion sequences (IS). Genes present on the reverse strand are denoted by the suffix $c$ following the locus tag (LSJ_XXX).

Additional file 2: Transposable elements and insertion sequence (IS) elements in the $L$. salivarius JCM1046 genome. Pseudogenes are denoted by $(P)$. Genes present on the reverse strand are denoted by the suffix c following the locus tag (LSJ_XXX).

Additional file 3: Genes harboured by the chromosome of strain JCM1046 that are absent from the chromosome of UCC118. Regions of diversity were determined using Panseq [59]. Pseudogenes are denoted by $(P)$. Genes present on the reverse strand are denoted by the suffix c following the locus tag (LSJ_XXX).

Additional file 4: Genes harboured by the chromosome of strain JCM1046 that are absent from other $L$. salivarius sequenced genomes. Gene presence/absence was determined by BLASTP sequence comparisons. Pseudogenes are denoted by $(P)$. Genes present on the reverse strand are denoted by the suffix $\mathrm{c}$ following the locus tag (LSJ_XXX)

Additional file 5: Exopolysaccharide gene cluster present on the chromosome of Lactobacillus salivarius JCM1046. Pseudogenes are denoted by $(P)$. Genes present on the reverse strand are denoted by the suffix $c$ following the locus tag (LSJ_XXX).

Additional file 6: Genes harboured by pCTN1046. Pseudogenes are denoted by $(P)$. Genes present on the reverse strand are denoted by the suffix $C$ following the locus tag (LSJ_XXX).

Additional file 7: Primers used to generate Southern Hybridization probes.

\section{Abbreviations}

aa: Amino acid; ACT: Artemis comparison tool; BLAST: Basic local alignment search tool; bp: Base pairs; CRISPR: Clustered regularly interspaced short palindromic repeats; CAS: CRISPR-associated sequence; DR: Direct repeat; EPS: Exopolysaccharide; GIT: Gastrointestinal tract; ID: Identity; IS: Insertion sequence; LAB: Lactic acid bacteria; LDL: Low-density lipoprotein; NCBI: National center for biotechnology information; PCR: Polymerase chain reaction; nr: Nonredundant protein database; nt: Nucleotides; sp: Species; TIR: Terminal inverted repeat

\section{Competing interests}

The authors declare that they have no competing financial interests.

\section{Authors' contributions}

EJR performed research, analyzed data and drafted the manuscript. BMF and MJC analyzed data and provided ongoing advice throughout the study. PWOT conceived the research, participated in its design and coordination, analyzed data and drafted the manuscript. All authors read and approved the final manuscript.

\section{Acknowledgements}

This research was supported by Science Foundation Ireland through a Research Frontiers 448 Programme award to PWOT (05/RFP/GEN047), and by a Centre for Science, Engineering and Technology award to the Alimentary Pharmabiotic Centre.

Received: 21 May 2014 Accepted: 26 August 2014

Published: 8 September 2014

\section{References}

1. Li Y, Raftis E, Canchaya C, Fitzgerald GF, Sinderen DV, O'Toole PW: Polyphasic analysis indicates that Lactobacillus salivarius subsp. salivarius and Lactobacillus salivarius subsp. salicinius do not merit separate subspecies status. Int J of Syst Evol Microbiol 2006, 56:2397-2403.

2. Reuter G: The Lactobacillus and Bifidobacterium microflora of the human intestine: composition and succession. Curr Issues Intest Microbiol 2001, 2(2):43-53.

3. Mitsuoka T: Vergleichende untersuchungen Über die Laktobazillen aus den faeces von menschen, schweinen und hühnern. Bakteriol 1969, 210:32-51.

4. Martín $\mathrm{R}$, Jiménez E, Olivares M, Marín ML, Fernández L, Xaus J, Rodríguez JM: Lactobacillus salivarius CECT 5713, a potential probiotic strain isolated from infant feces and breast milk of a mother-child pair. Int $\mathrm{J}$ Food Microbiol 2006, 112(1):35-43.

5. Neville BA, O'Toole PW: Probiotic properties of Lactobacillus salivarius and closely related Lactobacillus species. Future Microbiol 2010, 5(5):759-774.

6. Ryan KA, Daly P, Li Y, Hooton C, O'Toole PW: Strain-specific inhibition of Helicobacter pylori by Lactobacillus salivarius and other lactobacilli. J Antimicrob Chemother 2008, 61(4):831-834.

7. Raftis EJ, Salvetti E, Torriani S, Felis GE, O'Toole PW: Genomic diversity of Lactobacillus salivarius. App/ Environ Microbiol 2011, 77(3):954-965.

8. Flynn S, van Sinderen D, Thornton GM, Holo H, Nes IF, Collins JK: Characterization of the genetic locus responsible for the production of ABP-118, a novel bacteriocin produced by the probiotic bacterium Lactobacillus salivarius subsp. salivarius UCC118. Microbiology 2002, 148(4):973-984.

9. Claesson MJ, Li Y, Leahy S, Canchaya C, van Pijkeren JP, Cerdeño-Tárraga AM, Parkhill J, Flynn S, O'Sullivan GC, Collins JK, Higgins D, Shanahan F, Fitzgerald GF, van Sinderen D, O'Toole PW: Multireplicon genome architecture of Lactobacillus salivarius. Proc Natl Acad Sci 2006, 103(17):6718-6723.

10. Corr SC, Li Y, Riedel CU, O'Toole PW, Hill C, Gahan CGM: Bacteriocin production as a mechanism for the antiinfective activity of Lactobacillus salivarius UCC118. Proc Natl Acad Sci 2007, 104(18):7617-7621.

11. Fang F, Li Y, Bumann M, Raftis EJ, Casey PG, Cooney JC, Walsh MA, O'Toole PW: Allelic variation of bile salt hydrolase genes in Lactobacillus salivarius does not determine bile resistance levels. J Bact 2009, 191(18):5743-5757.

12. Li Y, Canchaya C, Fang F, Raftis E, Ryan KA, van Pijkeren J-P, van Sinderen D, O'Toole PW: Distribution of megaplasmids in Lactobacillus salivarius and other lactobacilli. J Bacteriol 2007, 189(17):6128-6139.

13. van Pijkeren J, Canchaya C, Ryan K, Li Y, Claesson M, Sheil B, Steidler L, O'Mahony L, Fitzgerald G, van Sinderen D: Comparative and functional analysis of sortase-dependent proteins in the predicted secretome of Lactobacillus salivarius UCC118. Appl Environ Microbiol 2006, 72(6):4143-4153.

14. Jimenez E, Martin R, Maldonado A, Martin V, Gomez de Segura A, Fernandez $L$, Rodriguez JM: Complete genome sequence of Lactobacillus salivarius CECT 5713, a probiotic strain isolated from human milk and infant feces. J Bacteriol 2010, 192(19):5266-5267.

15. Ham J-S, Kim H-W, Seol K-H, Jang A, Jeong S-G, Oh M-H, Kim D-H, Kang D-K, Kim G-B, Cha C-J: Genome sequence of Lactobacillus salivarius NIAS840, isolated from chicken intestine. J Bacterio/ 2011, 193(19):5551-5552. 
16. Kergourlay G, Messaoudi S, Dousset X, Prévost H: Genome Sequence of Lactobacillus salivarius SMXD51, a Potential Probiotic Strain Isolated from Chicken Cecum, Showing Anti-Campylobacter Activity. J Bacteriol 2012, 194(11):3008-3009.

17. Cho Y-J, Choi JK, Kim J-H, Lim Y-S, Ham J-S, Kang D-K, Chun J, Paik H-D, Kim G-B: Genome sequence of Lactobacillus salivarius GJ-24, a probiotic strain isolated from healthy adult intestine. J Bacterio/ 2011, 193(18):5021-5022.

18. MacKenzie DA, McLay K, Roos S, Walter J, Swarbreck D, Drou N, Crossman LC, Juge N: Draft Genome Sequence of a Novel Lactobacillus salivarius Strain Isolated from Piglet. Genome Announcements 2014, 2:1.

19. Overhage J, Sielker S, Homburg S, Parschat K, Fetzner S: Identification of large linear plasmids in Arthrobacter spp. encoding the degradation of quinaldine to anthranilate. Microbiology 2005, 151(2):491-500.

20. Kinashi H: Giant linear plasmids in Streptomyces: a treasure trove of antibiotic biosynthetic clusters. J Antibiot 2011, 64(1):19-25.

21. Chater K, Kinashi H: Streptomyces; linear plasmids: their discovery, functions, interactions with other replicons, and evolutionary significance. In Microbial Linear Plasmids, Volume 7. Edited by Meinhardt F Klassen R. Heidelberg: Springer Berlin; 2007:1-31.

22. Chen C: Streptomyces; linear plasmids: replication and telomeres. In Microbial Linear Plasmids, Volume 7. Edited by Meinhardt F, Klassen R. Springer Berlin: Heidelberg; 2007:33-61.

23. Barbour A, Garon C: Linear plasmids of the bacterium Borrelia burgdorferi have covalently closed ends. Science 1987, 237(4813):409-411.

24. Stromsten NJ, Benson SD, Burnett RM, Bamford DH, Bamford JKH: The Bacillus thuringiensis linear double-stranded DNA phage Bam35, which Is highly similar to the Bacillus cereus linear plasmid pBClin15, has a prophage state. J Bacteriol 2003, 185(23):6985-6989.

25. Ravin NV: N15: The linear phage-plasmid. Plasmid 2011, 65(2):102-109.

26. Hertwig S, Klein I, Lurz R, Lanka E, Appel B: PY54, a linear plasmid prophage of Yersinia enterocolitica with covalently closed ends. Mol Microbiol 2003, 48(4):989-1003.

27. Casjens SR, Gilcrease EB, Huang WM, Bunny KL, Pedulla ML, Ford ME, Houtz JM, Hatfull GF, Hendrix RW: The pKO2 linear plasmid prophage of Klebsiella oxytoca. J Bacteriol 2004, 186(6):1818-1832.

28. Alemayehu D, Ross RP, O'Sullivan O, Coffey A, Stanton C, Fitzgerald GF, McAuliffe O: Genome of a virulent bacteriophage Lb338-1 that lyses the probiotic Lactobacillus paracasei cheese strain. Gene 2009, 448(1):29-39.

29. Roussel Y, Colmin C, Simonet JM, Decaris B: Strain characterization, genome size and plasmid content in the Lactobacillus acidophilus group (Hansen and Mocquot). J Appl Bacteriol 1993, 74:549-556.

30. Franke $A E$, Clewell DB: Evidence for a chromosome-borne resistance transposon (Tn916) in Streptococcus faecalis that is capable of "conjugal" transfer in the absence of a conjugative plasmid. J Bacterio/ 1981, 145(1):494-502.

31. Clewell DB, Flannagan SE, Jaworski DD: Unconstrained bacterial promiscuity: the Tn916-Tn1545 family of conjugative transposons. Trends Microbiol 1995, 3(6):229-236.

32. Bertram J, Stratz M, Durre P: Natural transfer of conjugative transposon Tn916 between gram-positive and gram-negative bacteria. J Bacterio/ 1991, 173(2):443-448.

33. Boguslawska J, Zycka-Krzesinska J, Wilcks A, Bardowski J: Intra- and interspecies conjugal transfer of Tn916-like elements from Lactococcus lactis in vitro and in vivo. Appl Environ Microbiol 2009, 75(19):6352-6360.

34. Devirgiliis C, Coppola D, Barile S, Colonna B, Perozzi G: Characterization of the Tn916 conjugative transposon in a food-borne strain of Lactobacillus paracasei. Appl Environ Microbiol 2009, 75(12):3866-3871.

35. Roberts AP, Cheah G, Ready D, Pratten J, Wilson M, Mullany P: Transfer of Tn916-like elements in microcosm dental plaques. Antimicrob Agents Chemother 2001, 45(10):2943-2946.

36. Schjørring S, Krogfelt KA: Assessment of bacterial antibiotic resistance transfer in the gut. Int J Microbiol 2010, 2011:Article ID 312956.

37. Wozniak R, Waldor M: Integrative and conjugative elements: mosaic mobile genetic elements enabling dynamic lateral gene flow. Nature reviews Microbiology 2010, 8(8):552-563.

38. Roberts AP, Mullany P: A modular master on the move: the Tn916 family of mobile genetic elements. Trends Microbiol 2009, 17(6):251-258.

39. Carver T, Thomson N, Bleasby A, Berriman M, Parkhill J: DNAPlotter: circular and linear interactive genome visualization. Bioinformatics 2009, 25:119-120.
40. Fang F, Flynn S, Li Y, Claesson MJ, van Pijkeren J-P, Collins JK, van Sinderen D, O'Toole PW: Characterization of endogenous plasmids from Lactobacillus salivarius UCC118. Appl Environ Microbiol 2008, 74(10):3216-3228.

41. Barton BM, Harding GP, Zuccarelli AJ: A general method for detecting and sizing large plasmids. Analyst Biochem 1995, 226(2):235-240.

42. Warner JE, Onderdonk AB: Method for Optimizing Pulsed-Field Gel Electrophoresis Banding Pattern Data. JMD 2003, 5(1):21-27.

43. Wang $H$, Roberts AP, Mullany P: DNA sequence of the insertional hot spot of Tn916 in the Clostridium difficile genome and discovery of a Tn916-like element in an environmental isolate integrated in the same hot spot. FEMS Microbiol Lett 2000, 192(1):15-20.

44. Harrison PW, Lower RPJ, Kim NKD, Young JPW: Introducing the bacterial chromid": not a chromosome, not a plasmid. Trends Microbiol 2010, 18(4):141-148.

45. Sanchez-Perez G, Mira A, Nyirő G, Pašić L, Rodriguez-Valera F: Adapting to environmental changes using specialized paralogs. Trends Genet 2008, 24(4):154-158

46. Wagenknecht M, Dib J, Thürmer A, Daniel R, Farías M, Meinhardt F: Structural peculiarities of linear megaplasmid, pLMA1, from Micrococcus luteus; interfere with pyrosequencing reads assembly. Biotechnol Lett 2010, 32(12):1853-1862.

47. Roberts AP, Chandler M, Courvalin P, Guédon G, Mullany P, Pembroke T, Rood JI, Jeffery Smith C, Summers AO, Tsuda M, Berg DE: Revised nomenclature for transposable genetic elements. Plasmid 2008, 60(3):167-173.

48. Zhou Y, Liang Y, Lynch KH, Dennis JJ, Wishart DS: PHAST: A fast phage search tool. Nucleic Acids Res 2011, 39(suppl 2):W347-W352.

49. Jore MM, Brouns SJJ, van der Oost J: RNA in Defense: CRISPRs Protect Prokaryotes against Mobile Genetic Elements. Cold Spring Harb Perspect Biol 2012, 4(6). http://cshperspectives.cshlp.org/content/4/6/a003657.full.pdf+html.

50. Jannière L, Gruss A, Ehrlich D: Plasmids. In Bacillus subtilis and other gram-positive bacteria. Edited by Sonenshein JAH AL, Losick R. Washington, D.C: American Society for Microbiology; 1993:625-644.

51. Alikhan N-F, Petty N, Ben Zakour N, Beatson S: BLAST Ring Image Generator (BRIG): simple prokaryote genome comparisons. BMC Genomics 2011, 12(1):402.

52. Bentley SD, Parkhill J: Comparative genomic structure of prokaryotes Annu Rev Genet 2004, 38(1):771-791.

53. Heavens D, Tailford LE, Crossman L, Jeffers F, MacKenzie DA, Caccamo M, Juge N: Genome Sequence of the Vertebrate Gut Symbiont Lactobacillus reuteri ATCC 53608. J Bacterio/ 2011, 193(15):4015-4016.

54. Beaurepaire C, Chaconas G: Mapping of essential replication functions of the linear plasmid Ip17 of $B$. burgdorferi by targeted deletion walking. Mol Microbiol 2005, 57(1):132-142.

55. Chang P-C, Cohen SN: Birdirectional replication from an internal origin in a linear Streptomyces plasmid. Science 1994, 265:952-954.

56. Ravin NV, Kuprianov W, Gilcrease EB, Casjens SR: Bidirectional replication from an internal ori site of the linear N15 plasmid prophage. Nucleic Acids Res 2003, 31(22):6552-6560.

57. Mardanov A, Ravin N: Functional characterization of the repA replication gene of linear plasmid prophage N15. Res Microbiol 2006, 157(2):176-183.

58. Shiffman D, Cohen SN: Reconstruction of Streptomyces linear plasmid replication from separately cloned DNA fragment: existence pf a cryptic origin of circular replication within the linear plasmid. Proc Natl Acad Sci U S A 1992, 89(89):6129-6133.

59. Laing C, Buchanan C, Taboada E, Zhang Y, Kropinski A, Villegas A, Thomas J, Gannon V: Pan-genome sequence analysis using Panseq: an online tool for the rapid analysis of core and accessory genomic regions. $B M C$ Bioinformatics 2010, 11(1):461.

60. Berger B, Pridmore R, Barretto C, Delmas-Julien F, Schreiber K, Arigoni F, Brüssow H: Similarity and Differences in the Lactobacillus acidophilus Group Identified by Polyphasic Analysis and Comparative Genomics. $J$ Bacteriol 2007, 189(4):1311-1321.

61. Joyce SA, MacSharry J, Casey PG, Kinsella M, Murphy EF, Shanahan F, Hill C, Gahan CGM: Regulation of host weight gain and lipid metabolism by bacterial bile acid modification in the gut. Proc Natl Acad Sci 2014, 111(20):7421-7426.

62. Messaoudi S, Manai M, Kergourlay G, Prévost H, Connil N, Chobert JM, Dousset X: Lactobacillus salivarius: Bacteriocin and probiotic activity. Food Microbiol 2013, 36(2):296-304. 
63. Barrett E, Hayes M, O'Connor P, Gardiner G, Fitzgerald GF, Stanton C, Ross RP, Hill C: Salivaricin P, one of a family of two-component antilisterial bacteriocins produced by intestinal isolates of Lactobacillus salivarius. Appl Environ Microbiol 2007, 73(11):3719-3723.

64. O'Shea EF, O'Connor PM, Raftis EJ, O'Toole PW, Stanton C, Cotter PD, Ross RP, Hill C: Production of Multiple Bacteriocins from a Single Locus by Gastrointestinal Strains of Lactobacillus salivarius. J Bacteriol 2011, 193(24):6973-6982.

65. Chen K, Reuter M, Sanghvi B, Roberts GA, Cooper LP, Tilling M, Blakely GW, Dryden DTF: ArdA proteins from different mobile genetic elements can bind to the EcoKI Type I DNA methyltransferase of E. coli K12. Biochimica et Biophysica Acta (BBA) - Proteins and Proteomics 2014, 1844(3):505-511.

66. Guérillot R, Da Cunha V, Sauvage E, Bouchier C, Glaser P: Modular evolution of TnGBSs, a new family of integrative and conjugative elements associating insertion sequence transposition, plasmid replication, and conjugation for their spreading. J Bacterio/ 2013, 195(9):1979-1990.

67. Panel F: Opinion of the Scientific Panel on additives and products or substances used in animal feed (FEEDAP) on the updating of the criteria used in the assessment of bacteria for resistance to antibiotics of human or veterinary importance. EFSA J 2005, 223:1-12.

68. Zerbino DR, Birney E: Velvet: Algorithms for de novo short read assembly using de Bruijn graphs. Genome Res 2008, 18(5):821-829.

69. Mardis ER: Next-Generation DNA Sequencing Methods. Annu Rev Genomics Hum Genet 2008, 9(1):387-402.

70. Chevreux B, Wetter TSS: Genome sequence assembly using trace signals and additional sequence information. Computer Science and Biology: Proceedings of the German Conference on Bioinformatics (GCB) 1999, 99:45-56.

71. Green P: PHRAP v 1.080812. 1999 [http://phrap.org]

72. Milne I, Bayer M, Cardle L, Shaw P, Stephen G, Wright F, Marshall D: Tabletnext generation sequence assembly visualization. Bioinformatics 2010, 26(3):401-402.

73. Forde B, Neville B, O' Donnell M, Riboulet-Bisson E, Claesson M, Coghlan A, Ross $R, O^{\prime}$ Toole P: Genome sequences and comparative genomics of two Lactobacillus ruminis strains from the bovine and human intestinal tracts. Microb Cell Fact 2011, 10(1):S13.

74. Otto TD, Dillon GP, Degrave WS, Berriman M: RATT: Rapid Annotation Transfer Tool. Nucleic Acids Res 2011.

75. Rutherford K, Parkhill J, Crook J, Horsnell T, Rice P, Rajandream M-A, Barrell B: Artemis: sequence visualization and annotation. Bioinformatics 2000 16(10):944-945.

76. Carver TJ, Rutherford KM, Berriman M, Rajandream MA, Barrell BG, Parkhill J: ACT: the Artemis comparison tool. Bioinformatics 2005, 21:3422-3423.

\section{Submit your next manuscript to BioMed Central and take full advantage of:}

- Convenient online submission

- Thorough peer review

- No space constraints or color figure charges

- Immediate publication on acceptance

- Inclusion in PubMed, CAS, Scopus and Google Scholar

- Research which is freely available for redistribution 